\title{
Effect of preweaned dairy calf housing system on antimicrobial resistance in commensal Escherichia coli
}

\author{
R. V. Pereira, ${ }^{* 1}$ J. D. Siler, ${ }^{*}$ J. C. Ng, ${ }^{*}$ M. A. Davis, $\dagger$ and L. D. Warnick* \\ *Department of Population Medicine and Diagnostic Sciences, College of Veterinary Medicine, Cornell University, Ithaca, NY 14853 \\ †Veterinary Microbiology and Pathology Department, Washington State University, Pullman 99164-7040
}

\begin{abstract}
Group housing of preweaned dairy calves is a growing practice in the United States. The objective of this practice is to increase the average daily gain of calves in a healthy and humane environment while reducing labor requirements. However, feeding protocols, commingling of calves, and occurrence of disease in different calf-housing systems may affect the prevalence of antimicrobial drug-resistant bacteria. This study evaluated the effect of a group pen-housing system and individual pen-housing system on antimicrobial resistance trends in fecal Escherichia coli of preweaned dairy calves and on the prevalence of environmental Salmonella. Twelve farms from central New York participated in the study: 6 farms using an individual pen-housing system (IP), and 6 farms using a group pen-housing system (GP). A maximum of 3 fecal $E$. coli isolates per calf was tested for susceptibility to 12 antimicrobial drugs using a Kirby-Bauer disk diffusion assay. Calves in GP had a significantly higher proportion of E. coli resistant to ciprofloxacin and nalidixic acid, whereas calves in IP had a significantly higher proportion of $E$. coli resistant to ampicillin, ceftiofur, gentamycin, streptomycin, and tetracycline. Calf-housing system had an effect on resistance to individual antimicrobial drugs in E. coli, but no clear-cut advantage to either system was noted with regard to overall resistance frequency. No outstanding difference in the richness and diversity of resistant phenotypes was observed between the 2 calf-housing systems.
\end{abstract}

Key words: antimicrobial resistance, calf-housing system, group housing, individual pens

\section{INTRODUCTION}

According to the last inventory report released by the USDA in January 2011, there were more than 14 million calves in the United States, of which 650,000 are

Received July 9, 2014.

Accepted September 4, 2014.

${ }^{1}$ Corresponding author: rvp25@cornell.edu estimated to be preweaned dairy calves (USDA, 2011). A growing practice on US dairies, especially in the northeast, is housing calves in group pens ranging from 12 to 25 calves, and feeding free-choice (ad libitum) acidified milk. Milk is acidified to a $\mathrm{pH}$ of 4.0 to 4.5 to preserve it by preventing bacteria and mold growth. This practice differs from the current conventional system where calves are housed in individual pens and fed predetermined amounts of milk or milk replacer for specific number of times during the day. The objective of group housing is to increase the ADG of calves in a healthy and humane environment while reducing labor requirements (Warnick et al., 1977; O'Driscoll et al., 2006; Bernal-Rigoli et al., 2012). One calf-housing study reported that the time needed to manage a calf in an individual pen is approximately $10 \mathrm{~min} /$ calf per day, but the time committed to management of a calf raised in a group pen is less than $1 \mathrm{~min} /$ calf per day (Kung et al., 1997). A potential disadvantage of group housing is that direct contact between calves in group pens could increase the risk of transmission of pathogens between calves and, potentially, the exchange of antimicrobial resistance.

The effect of group penning on calf health is not clear and the practice remains controversial (Wells et al., 1997). Housing calves in group pens was observed by Linton et al. (1974) to result in a higher incidence of salmonellosis, with a $10.5 \%$ average incidence in calves housed in group pens compared with a $1.1 \%$ average incidence in calves housed in individual pens. WaltnerToews et al. (1986), in a study of dairy calf management, morbidity, and mortality in Ontario Holstein herds, observed that the direction of group penning effects on calf morbidity relative to individual pens was not consistent. They observed that the odds ratio of scours or pneumonia for calves housed either in group pens or individual pens was not significantly different, and that any effects appeared to be minimal.

Commingling of calves, feeding protocols, and incidence of disease are a few differences between calves housed in group pens and calves housed in individual pens that could result in a distinct prevalence of antimicrobial drug resistance. The objective of our study 
was to evaluate the effects of these 2 calf-housing systems - calves in individual pens fed milk or milk replacer 2 to 3 times a day and calves in group pens fed free-choice acidified milk - on antimicrobial resistance trends in fecal Escherichia coli and on the prevalence of environmental Salmonella.

\section{MATERIALS AND METHODS}

\section{Inclusion Criteria for Farms}

Farms were eligible for inclusion in the present study if their calf-housing system consisted of either (1) housing calves in individual pens while feeding them milk or milk replacer (IP) or (2) housing calves in group pens while feeding them acidified milk ad libitum (GP). In addition, farms participating in the current study could not add any antimicrobial drugs to the milk fed to preweaned calves. A total of 658 preweaned dairy calves were enrolled from 12 farms in central New York (Table 1). Herds were selected from a convenience sample of commercial dairy farms within a 3 -h radius of Cornell University (Ithaca, NY). Dairy farms were located in the following counties in central New York State: Cayuga, Cortland, Onondaga, Ontario, Tompkins, and Wayne. Farmers were requested to answer a short questionnaire on calf management practices on the dairy.

\section{Study Design and Sample Collection}

Our study used a cross-sectional design in which rectal swabs were collected from preweaned dairy calves during a single farm visit. At each farm, preweaned calves were divided into 3 age groups and approximately the same numbers of total samples were collected from each age group using a randomization spreadsheet. The randomization spreadsheet was created using the random number function of Excel (Microsoft, Redmond, WA). The age groups were (1) 3 to 14 , (2) 15 to 35 , and (3) 36 to 65 d of age. All calves enrolled in the present study were female. Environmental samples were collected from the pen floors and feeder nipples of group pens in GP farms, and the pen floor and hutches of calf pens in IP farms. Farm sampling was conducted from July to October 2012.

\section{Bacterial Isolation, Culture, and Identification}

Transport swabs with Amies medium were used to collect individual rectal fecal samples from calves (Becton Dickinson and Company, Franklin Lakes, NJ). Individual fecal swabs were streaked onto MacConkey agar plates on the day of collection and incubated overnight at $37^{\circ} \mathrm{C}$. Up to $3 \mathrm{E}$. coli isolates were confirmed as $E$. coli and stored in Luria-Bertani broth containing $20 \%$ glycerol at $-80^{\circ} \mathrm{C}$, as previously described (Pereira et al., 2011). A total of 1,960 E. coli isolates were obtained from fecal swab cultures (Table 1).

Standard bacteriologic culture methods were used to isolate Salmonella from environmental samples. Individual swab specimens from each sample were enriched in $10 \mathrm{~mL}$ of Tetrathionate broth (Difco, Detroit, MI) containing $0.2 \mathrm{~mL}$ of iodine solution; the mixture was incubated at $42^{\circ} \mathrm{C}$ for 18 to $24 \mathrm{~h}$. After incubation, the sample-broth mixture was streaked onto Brilliant Green agar with novobiocin (Northeast Laboratory, Waterville, Maine) and xylose lysine tergitol 4 (XLT-4) selective media, and both plates were incubated at $37^{\circ} \mathrm{C}$

Table 1. Total number of calves, Escherichia coli isolates, and average age of calves in the study by calfhousing system

\begin{tabular}{|c|c|c|c|}
\hline Description & $\begin{array}{l}\text { No. of } \\
\text { calves }\end{array}$ & $\begin{array}{l}\text { No. of } \\
E . \text { coli } \\
\text { isolates }\end{array}$ & $\begin{array}{c}\text { Mean age in days } \\
\text { (minimum; maximum) }\end{array}$ \\
\hline \multicolumn{4}{|l|}{$\mathrm{IP}^{1}$} \\
\hline $\mathrm{AG}-1^{2}$ & 92 & 275 & $8(0 ; 14)$ \\
\hline $\mathrm{AG}-2^{3}$ & 128 & 379 & $26(15 ; 35)$ \\
\hline $\mathrm{AG}-3^{4}$ & 83 & 249 & $48(36 ; 65)$ \\
\hline Total & 303 & 903 & \\
\hline \multicolumn{4}{|l|}{$\mathrm{GP}^{5}$} \\
\hline $\mathrm{AG}-1^{2}$ & 94 & 278 & $9(1 ; 14)$ \\
\hline AG- $2^{3}$ & 129 & 383 & $28(15 ; 35)$ \\
\hline $\mathrm{AG}-3^{4}$ & 132 & 396 & $42(37 ; 62)$ \\
\hline Total & 355 & 1,057 & \\
\hline Overall Total & 658 & 1,960 & \\
\hline \multicolumn{4}{|c|}{${ }^{1}$ Calves housed in individual pens without direct contact with neighboring calves and fed milk or milk replacer } \\
\hline \multirow{2}{*}{\multicolumn{4}{|c|}{$\begin{array}{l}2 \text { to } 3 \text { times a day. } \\
{ }^{2} \text { Calves with ages between } 0 \text { to } 14 \mathrm{~d} \text {. }\end{array}$}} \\
\hline \multirow{2}{*}{\multicolumn{3}{|c|}{$\begin{array}{l}{ }^{2} \text { Calves with ages between } 0 \text { to } 14 \mathrm{~d} \text {. } \\
{ }^{3} \text { Calves with ages between } 15 \text { to } 35 \mathrm{~d} \text {. }\end{array}$}} & \\
\hline & & & \\
\hline \multicolumn{4}{|c|}{${ }^{4}$ Calves with ages between 35 to $65 \mathrm{~d}$. } \\
\hline
\end{tabular}


for 18 to $24 \mathrm{~h}$. Red colonies (lactose-nonfermenting bacteria) on Brilliant Green agar with novobiocin and black colonies (hydrogen sulfide-producing bacteria) on XLT-4 were inoculated into Kligler Iron Agar slants and incubated at $37^{\circ} \mathrm{C}$ for 18 to $24 \mathrm{~h}$. The XLT-4 plates without suspected colonies were reincubated at $37^{\circ} \mathrm{C}$ for an additional 18 to $24 \mathrm{~h}$ before checking again for characteristic black colonies. If a Kligler Iron Agar slant exhibited the biochemical properties of Salmonella, the isolate was confirmed by slide agglutination using Salmonella O Antiserum Poly A-I \&Vi (Becton Dickinson and Company). Confirmed Salmonella isolates were stored in Luria-Bertani broth containing $20 \%$ glycerol at $-80^{\circ} \mathrm{C}$. Additionally, 1 confirmed Salmonella isolate from each sample was sent to the National Veterinary Services Laboratories in Ames, Iowa, for serotyping.

Antimicrobial susceptibility of E. coli and Salmonella isolates was tested for a modified National Antimicrobial Resistance Monitoring system panel of 12 antimicrobial drugs. National Antimicrobial Resistance Monitoring was established in 1996 by the Food and Drug Administration's Center for Veterinary Medicine in collaboration with the Centers for Disease Control and Prevention and the USDA in an effort to prospectively monitor the occurrence of antimicrobial resistance of zoonotic pathogens from human diagnostic specimens, retail meats, and food animals. The susceptibility testing test was done using a Kirby-Bauer disk diffusion agar assay in accordance with the guidelines published by the Clinical and Laboratory Standards Institute (CLSI) and methodology previously described (CLSI, 2008b; Hoelzer et al., 2011; Pereira et al., 2011). Internal quality control was performed by inclusion of $E$. coli ATCC 25922, previously determined to be pansusceptible, as well as a previously characterized in-house $E$. coli isolate known to have a $b l a_{C M Y-2}$ gene and to be resistant to 9 of the antimicrobials tested. All susceptibility results of quality control strains complied with the quality control ranges. Antimicrobial susceptibility for all isolates was assessed using the following panel: ampicillin, $10 \mu \mathrm{g}$; cefoxitin, $30 \mu \mathrm{g}$; ceftiofur, $30 \mu \mathrm{g}$; ceftriaxone, $30 \mu \mathrm{g}$; chloramphenicol, $30 \mu \mathrm{g}$; ciprofloxacin, $5 \mu \mathrm{g}$; gentamicin, $10 \mu \mathrm{g}$; nalidixic acid, $30 \mu \mathrm{g}$; neomycin, $30 \mu \mathrm{g}$; streptomycin, $10 \mu \mathrm{g}$; tetracycline, $30 \mu \mathrm{g}$; and trimethoprim-sulfamethoxazole, 23.75/1.25 $\mu \mathrm{g}$. Susceptibility of the isolates to most antimicrobial drugs was categorized (susceptible, intermediate, or resistant) by measuring the inhibition zone according to interpretive criteria adhering to the CLSI guidelines (CLSI, 2008a).

\section{Statistical Analyses}

Escherichia coli isolates were categorized as susceptible, intermediate, or resistant in accordance with
CLSI guidelines as described previously. The herd-level effect from the group-housing system on the proportion of calves resistant to antimicrobial drugs was estimated using generalized linear models (GLM). For our analysis, a calf was considered positive for resistance if at least 1 of the $E$. coli was classified as resistant. The herd-level proportion of calves resistant to individual antimicrobial drugs was determined using PROC MEAN in SAS (SAS Institute Inc., Cary, NC). The GLM for each antimicrobial drug tested were created using PROC GLM in SAS. For these herd-level analyses, the dependent variable was the proportion of resistant calves per farm sampled and the independent variable was calf-housing system (IP and GP). The assumption of normal distribution of residuals was analyzed using PROC UNIVARIATE in SAS and by visually evaluating the distribution plot of the residuals. Assumption of normal distribution of residuals was satisfied.

To evaluate the effect of calf-housing system on the odds of $E$. coli resistance, multivariable mixed logistic regression models were fitted to the data using the GLIMMIX procedure of SAS. The variables calf-housing system (IP or GP) and age group (3 to 14, 15 to 35 , and 36 to $65 \mathrm{~d}$ of age) were included in all models as independent variables and the variable for individual identification of each calf (to account for clustering within calf) was nested within the herd variable and included in all models as a random effects.

Antimicrobial drug susceptibility phenotypes (ADSP) consisted of patterns of resistance to the antimicrobial drugs, including a pansusceptible phenotype. Diversity and richness of ADSP at the pen and farm levels were estimated using the 9.1 version of the software EstimateS (Colwell, 2013). Pens represented by less than $6 \mathrm{E}$. coli isolates were considered inadequate for our analysis and a total of 4 pens (total of $17 E$. coli isolates) from GP farms were excluded from this analysis. Richness was calculated using the Chao richness index and by using rarefaction curves, which are produced by repeatedly sampling all of the collected species at random and computing the expected number of species as a function number of accumulated samples (MacGregor-Fors and Payton, 2013). Diversity was estimated using the Shannon diversity index. Rarefaction curves, Chao index, and Shannon index were estimated by calf-housing system type at the pen and herd level. To compare the richness, diversity, and biotic similarity of antimicrobial susceptibility phenotypes at the pen level for IP farms, mock group pens were created. This was done by (1) matching an IP farm to a GP farm by total number of lactating cows; (2) ordering GP pens at the farm level according to the average calf age in days in each pen and determining the proportion of total sampled calves present in each pen; and (3) ordering 
all calves sampled for each IP farm at the farm level by age in days and distributing them in the same number of pens present in the matched GP farm following the same proportion of total sampled calves present in each pen using the age in days range as a guide.

Escherichia coli ADSP similarities between pairs of calves were assessed using the Sorensen and Jaccard incidence-based similarity indices. The Jaccard index compares the number of shared species to the total number of species in the combined assemblages, whereas the Sorensen index compares the number of shared species to the mean number of species in a single assemblage (Gotelli and Chao, 2013). Additionally, the Chao-Sorensen abundance-based similarity index was used to measure E. coli ADSP similarity. Similarity indices were calculated at the pen and farm level using EstimateS (Colwell, 2013). Both the incidence- and abundance-based similarity indices range from 0 to 1 , with 0 indicating that no susceptibility phenotypes are shared between a pair of calves and 1 indicating complete identity (all the susceptibility phenotypes present in calf 1 were also present in calf 2 and vice versa). The similarity indices are shown as a percentage in the results by multiplying the index by 100 .

Descriptive analysis of $E$. coli resistance phenotypes and environmental samples cultured for Salmonella was conducted using PROC FREQ in SAS. In our study, multidrug resistance was defined as having resistance to $\geq 3$ antimicrobial agents. For all statistical models and tests, variables were considered significant when a $P \leq 0.05$ was observed.

\section{RESULTS}

\section{Descriptive Data}

A total of 12 farms participated in our study, with 6 farms using a GP housing system for calves and 6 farms using an IP housing system for calves. The number of calves in a group pen at GP farms ranged from to 6 to10 calves for 2 farms, 15 to 20 calves for 2 farms, and 20 to 26 calves for 2 farms. For all GP farms, calves were added to a group pen according to birth order until the desired number of calves for the pen was reached. For both GP and IP farms, 1 farm had less than 200 lactating cows, 2 farms had 500 to 1,000 lactating cows, and 3 farms had more than 1,000 lactating dairy cows. The total number of calves and E. coli isolates and the average age of calves in the study by calf-housing system are shown in Table 1 . The 2 most commonly reported antimicrobial drugs used for calves in the group housing system were enrofloxacin (Bayer Animal Health, Shawnee Mission, KS) and tulathromycin (Draxxin Injectable Solution, Pfizer Animal Health, New York,
$\mathrm{NY}$ ). Information on the 2 most common antimicrobial drugs used on farms with individual-housing systems, ceftiofur (Excenel RTU, Pfizer Animal Health) and penicillin $\mathrm{G}$, was available for 3 of 6 farms and were.

\section{Antimicrobial Resistance in E. coli Isolates}

At the herd level, calf-housing systems did not have a significant effect on the proportion of antimicrobial resistance (Table 2). At the calf level, IP farms had a significantly greater number of resistant isolates per calf compared with GP farms for 1 or more age groups for ampicillin, ceftiofur, gentamicin, streptomycin, and tetracyline (Table 3). The GP farms had a significantly greater number of resistant isolates per calf compared with IP farms for ciprofloxacin $(P<0.0001)$ and nalidixic acid $(P=0.001$; Table 3$)$. No significant difference between the numbers of resistant isolates per calf for calf-housing systems by age group was observed for any of the antimicrobials tested.

\section{Distribution of E. coli Antimicrobial Susceptibility Phenotypes}

Of the 903 E. coli isolates from IP calves, $11.7 \%$ were pansusceptible and $75.5 \%$ were multidrug resistant. Of the 1,057 isolates from GP calves, $18.2 \%$ were pansusceptible and $69.1 \%$ were multidrug resistant. The most common multidrug-resistant phenotype observed in IP isolates was ampicillin-cefoxitin-ceftiofur-streptomycin-tetracycline $(5.4 \%)$, whereas for GP isolates chloramphenicol-streptomycin-tetracycline $(7.3 \%)$ was the most common (Table 4).

Figure 1 shows the rarefaction curves where isolates were clustered by pen and by farm for IP and GP. The mean Chao richness index for E. coli ADSP was 11.5 and 29.3 for IP isolates $(\mathrm{n}=903)$ and 10.1 and 29.7 for GP isolates $(\mathrm{n}=1,040)$ at the pen and farm level, respectively (Table 5). The mean Shannon diversity index for E. coli ADSP at the pen and farm level were 1.6 and 2.4 for IP isolates $(\mathrm{n}=903)$ and 1.5 and 2.3 for GP isolates, respectively $(\mathrm{n}=1,040$; Table 5$)$.

Within each calf-housing system, both incidence(Jaccard and Sorensen) and abundance-based (ChaoSorensen) similarity indices for E. coli ADSP were higher between pairs of calves at the pen level compared with the farm level (Table 5). When similarity indexes were compared between calf-housing systems, both incidence- and abundance-based similarity indexes calculated either at the pen or farm level were slightly higher for GP (Table 5).

\section{Distribution of Environmental Salmonella Serovars}

Among the 122 environmental samples, 36\% were positive for Salmonella. Of these, 25 Salmonella isolates 
Table 2. Herd-level effect of calf-housing system on the proportion of antimicrobial-resistant Escherichia coli

\begin{tabular}{lccc}
\hline & \multicolumn{3}{c}{$\mathrm{PR}^{1}$} \\
\cline { 2 - 3 } Antimicrobial & $\mathrm{IP}(\mathrm{n}=6)$ & $\mathrm{GP}(\mathrm{n}=6)$ & $P$-value \\
\cline { 2 - 3 } agent & 80.0 & 72.6 & 0.43 \\
Ampicillin & 48.9 & 59.1 & 0.73 \\
Cefoxitin & 29.6 & 25.1 & 0.85 \\
Ceftiofur & 8.0 & 4.0 & 0.43 \\
Ceftriaxone & 42.6 & 45.7 & 0.75 \\
Chloramphenicol & 1.8 & 9.0 & 0.16 \\
Ciprofloxacin & 21.2 & 5.8 & 0.73 \\
Gentamicin & 2.5 & 10.3 & 0.12 \\
Nalidixic acid & 53.3 & 46.9 & 0.69 \\
Neomycin & 83.1 & 72.9 & 0.18 \\
Streptomycin & 87.2 & 79.1 & 0.24 \\
Tetracycline & 45.4 & 54.3 & 0.49 \\
TMS & & & \\
\hline PR & & & \\
\hline
\end{tabular}

${ }^{1} \mathrm{PR}=$ proportion of calves with resistant $E$. coli isolates by calf-housing system (IP or GP); IP = calves housed in individual pens without direct contact with neighboring calves and fed milk or milk replacer 2 to 3 times a day; GP $=$ calves housed in group pens with 3 to 25 calves being fed free-choice acidified milk.

${ }^{2}$ Trimethoprim sulfamethoxazole.

were from IP farms and 19 Salmonella isolates were from GP farms. The Salmonella serovars identified in IP isolates were Cerro $(\mathrm{n}=23)$ and Liverpool $(\mathrm{n}=2)$, whereas for GP isolates Cerro $(\mathrm{n}=11)$ and Newport (n $=8$ ) were observed (Table 6). All Salmonella isolates from IP farms and all Cerro isolates were pansusceptible. Eight Newport isolates had the same multidrugresistant phenotype ampicillin-cefoxitin-ceftiofur-chloramphenicol-neomycin-streptomycin-tetracycline and belonged to a single GP farm.

\section{DISCUSSION}

\section{Antimicrobial Resistance in E. coli Isolates}

The GP calves had a higher prevalence of resistance to antimicrobials belonging to the quinolone class than did IP calves, with 0.2 and 0.3 odds for resistance in IP compared with GP for ciprofloxacin $(P<0.0001)$ and nalidixic acid $(P=0.001$; Table 3$)$. Escherichia coli from calf feces typically are not resistant to ciprofloxa-

Table 3. Effect of calf-housing management (IP or GP) and calf age group (AG-1, AG-2 or AG-3) on Escherichia coli resistance while controlling for the random effect of herd and calf

\begin{tabular}{|c|c|c|c|c|c|c|c|c|c|c|}
\hline \multirow{2}{*}{$\begin{array}{l}\text { Antimicrobial } \\
\text { agent }\end{array}$} & \multicolumn{2}{|c|}{$\begin{array}{c}\text { Resistance, } \\
\%\end{array}$} & \multicolumn{2}{|c|}{ Odds ratio, $95 \%$ CI } & \multicolumn{3}{|c|}{ Resistance, \% } & \multicolumn{3}{|c|}{ Odds ratio, $95 \%$ CI } \\
\hline & $\mathrm{IP}^{1}$ & $\mathrm{GP}^{2}$ & IP vs. $\mathrm{GP}^{3}$ & $P$-value ${ }^{4}$ & $\mathrm{AG}-1^{5}$ & $\mathrm{AG}-2^{6}$ & $\mathrm{AG}-3^{7}$ & AG-1 vs. $A G-3^{8}$ & AG- 2 vs. AG- $3^{9}$ & $P$-value ${ }^{10}$ \\
\hline Cefoxitin & 46 & 47 & $0.7(0.3 ; 1)$ & 0.4 & 52 & 43 & 45 & $2.0(0.9 ; 6)$ & $1.0(0.5 ; 3)$ & 0.14 \\
\hline Ceftiofur & 33 & 27 & $2.0(1 ; 5)$ & 0.02 & 29 & 35 & 25 & $2.0(0.8 ; 5)$ & $4.0(2 ; 10)$ & 0.004 \\
\hline Ceftriaxone & 10 & 5 & $2.0(0.8 ; 7)$ & 0.1 & 5 & 10 & 6 & $0.9(0.4 ; 2)$ & $0.8(0.3 ; 2)$ & 0.7 \\
\hline Gentamicin & 16 & 4 & $5.0(1 ; 19)$ & 0.03 & 7 & 8 & 12 & $0.5(0.1 ; 2)$ & $0.7(0.1 ; 3)$ & 0.7 \\
\hline Nalidixic acid & 1 & 7 & $0.3(0.1 ; 0.6)$ & 0.001 & 0.5 & 4 & 9 & $0.1(0.03 ; 0.3)$ & $0.5(0.2 ; 1)$ & 0.006 \\
\hline Neomycin & 32 & 32 & $1.0(0.8 ; 1)$ & 0.6 & 42 & 29 & 26 & $2.0(2 ; 3)$ & $1.0(0.9 ; 1)$ & $<0.0001$ \\
\hline Streptomycin & 70 & 58 & $4.0(2 ; 7)$ & $<0.0001$ & 67 & 59 & 65 & $1.0(0.5 ; 2)$ & $0.5(0.2 ; 1)$ & 0.14 \\
\hline Tetracycline & 77 & 70 & $2.0(1 ; 5)$ & 0.04 & 79 & 70 & 72 & $2.0(0.8 ; 6)$ & $0.6(0.2 ; 1)$ & 0.02 \\
\hline $\mathrm{TMS}^{11^{\circ}}$ & 33 & 37 & $0.6(0.3 ; 1)$ & 0.1 & 49 & 30 & 30 & $8.0(3 ; 19)$ & $1.0(0.5 ; 2)$ & $<0.0001$ \\
\hline
\end{tabular}

${ }^{1} \mathrm{IP}=$ calves housed in individual pens without direct contact with neighboring calves and fed milk or milk replacer 2 to 3 times a day.

${ }^{2} \mathrm{GP}=$ calves housed in group pens with 3 to 25 calves being fed free-choice acidified milk.

${ }^{3}$ Odds ratio for resistance in IP when compared with GP.

${ }^{4} P$-value for calf-housing management (IP or GP).

${ }^{5}$ Age group with a range between 0 to $14 \mathrm{~d}$ old (AG-1).

${ }^{6}$ Age group with a range between 15 to $35 \mathrm{~d}$ old (AG-2).

${ }^{7}$ Age group with a range between 36 to $65 \mathrm{~d}$ old (AG-3).

${ }^{8}$ Odds ratio for resistance in AG-1 when compared with AG-3.

${ }^{9}$ Odds ratio for resistance in AG-2 when compared with AG-3.

${ }^{10} P$-value for age group (AG-1, AG-2, and AG-3).

${ }^{11}$ Trimethoprim sulfamethoxazole. 
Table 4. Most common multidrug-resistant phenotypes among 1,960 Escherichia coli from calves by calfhousing system

\begin{tabular}{lcc}
\hline Resistant phenotype $^{1}$ & $\begin{array}{c}\text { No. of } \\
\text { isolates }\end{array}$ & $\begin{array}{c}\% \text { of } \\
\text { isolates }\end{array}$ \\
\hline IP $^{2}(\mathrm{n}=903)$ & & \\
AMP-FOX-TIO-STR-TET & 49 & 5.4 \\
AMP-FOX-CHL-STR -TET & 45 & 4.9 \\
AMP-FOX-CHL-GEN-STR-TET & 31 & 3.4 \\
Pansusceptible & 106 & 11.7 \\
GP $^{3}(\mathrm{n}=1057)$ & 78 & 7.3 \\
CHL-STR-TET & 59 & 5.6 \\
AMP-FOX-TIO-NEO-STR-TET-COT & 42 & 4.0 \\
AMP-FOX-CHL-NEO-STR-TET-COT & 193 & 18.2 \\
Pansusceptible & & \\
\hline
\end{tabular}

${ }^{1} \mathrm{AMP}=$ ampicillin $; \mathrm{FOX}=$ cefoxitin TIO $=$ ceftiofur; $\mathrm{CHL}=$ chloramphenicol; GEN = gentamicin; $\mathrm{NEO}=$ neomycin; STR = streptomycin; COT $=$ trimethoprim sulfamethoxazole; TET $=$ tetracycline.

${ }^{2} \mathrm{IP}=$ calves housed in individual pens without direct contact with neighboring calves and fed milk or milk replacer 2 to 3 times a day.

${ }^{3} \mathrm{GP}=$ calves housed in group pens with 3 to 25 calves being fed free-choice acidified milk.

cin and nalidixic acid, and this resistance is an uncommon finding, as reported in other calf studies (Gow et al., 2008; Pereira et al., 2011). However, a recent study that inclusively screened calf $E$. coli isolates received by the Cornell University Animal Health Diagnostic Center from 2004 to 2011 observed that resistance to enrofloxacin has increased from 1.0\% (6/574) in 2004 to $8.1 \%$ (15/185) in 2011 (Cummings et al., 2014). The observed higher prevalence of resistance to quinolone drugs is a major area of concern, because they are regarded as critically important antimicrobial agents for human medicine according to the World Health
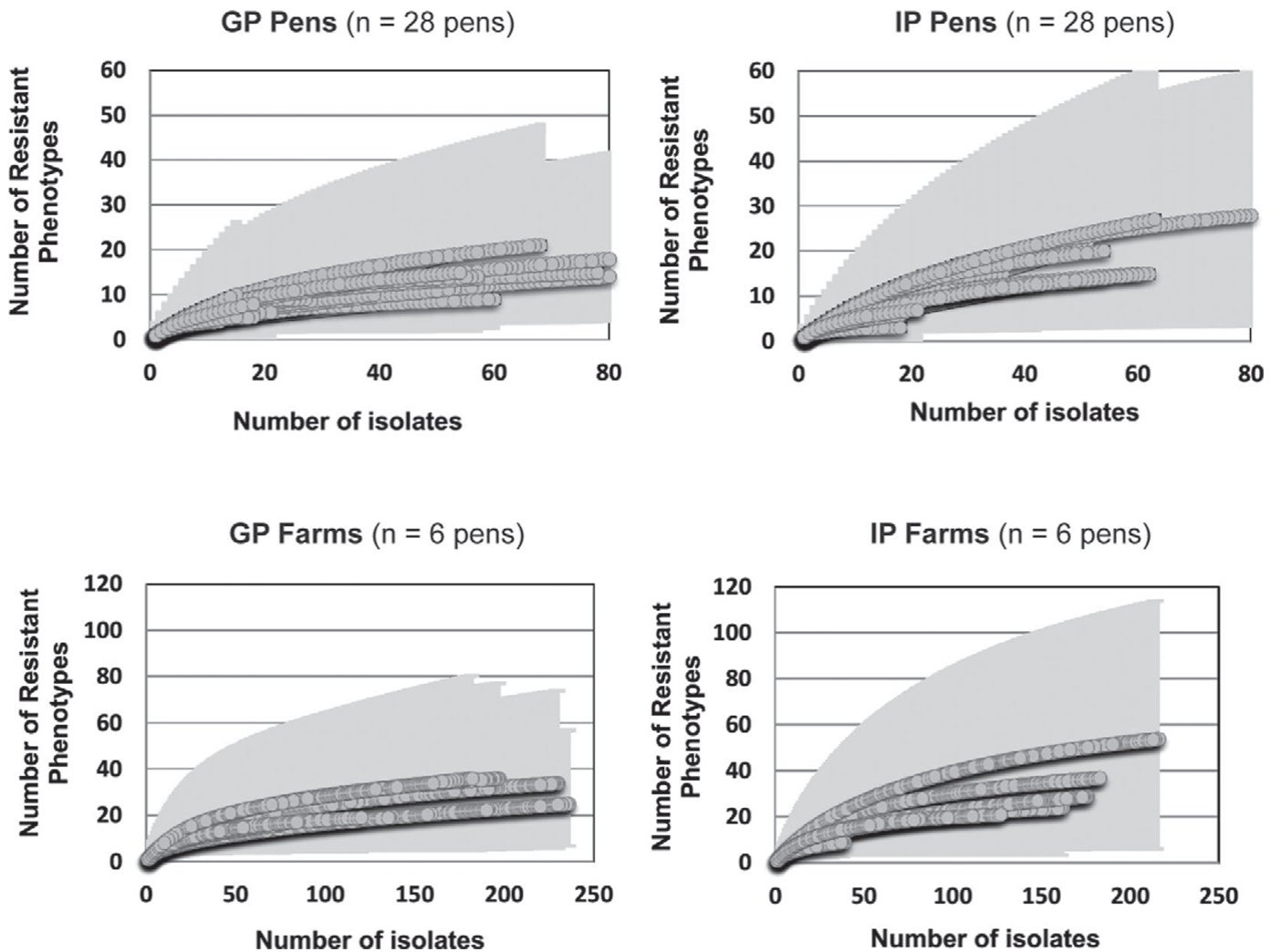

Figure 1. Rarefaction curves for the number of Escherichia coli antimicrobial drug susceptibility phenotypes. Shaded area corresponds to a 95\% CI. Calves housed in group pens (GP) had 3 to 25 calves fed free-choice acidified milk. Calves housed in individual pens (IP) had no direct contact with neighboring calves and were fed milk or milk replacer 2 to 3 times a day. 
Table 5. Mean richness, diversity, and biotic similarity of Escherichia coli antimicrobial drug susceptibility phenotypes

\begin{tabular}{|c|c|c|c|c|}
\hline \multirow[b]{2}{*}{ Description } & \multicolumn{2}{|c|}{$\mathrm{IP}^{1}(\mathrm{n}=903$ isolates $)$} & \multicolumn{2}{|c|}{$\mathrm{GP}^{2}(\mathrm{n}=1,040$ isolates $)$} \\
\hline & $\begin{array}{c}\text { Pen }^{3} \\
(\mathrm{n}=29 \text { pens })\end{array}$ & $\begin{array}{c}\text { Farm }^{4} \\
(\mathrm{n}=6 \text { farms })\end{array}$ & $\begin{array}{c}\text { Pen }^{3} \\
(\mathrm{n}=29 \text { pens })\end{array}$ & $\begin{array}{c}\text { Farm }^{4} \\
(\mathrm{n}=6 \text { farms })\end{array}$ \\
\hline \multicolumn{5}{|l|}{ Richness } \\
\hline Chao index & $11.5(3.7 ; 19.3)$ & $29.3(8.5 ; 55.1)$ & $10.1(5.5 ; 13.4)$ & $29.7(16.8 ; 43.0)$ \\
\hline \multicolumn{5}{|l|}{ Diversity } \\
\hline Shannon index & $1.6(1.0 ; 2.0)$ & $2.45(1.5 ; 3.1)$ & $1.5(1.1 ; 1.8)$ & $2.36(1.9 ; 2.8)$ \\
\hline \multicolumn{5}{|l|}{ Similarity, ${ }^{5} \%$} \\
\hline Shared ${ }^{6}$ & $33(3 ; 80)$ & $29(11 ; 65)$ & $37(6 ; 73)$ & $31(13 ; 54)$ \\
\hline Jaccard index & $13(2 ; 53)$ & $11(4 ; 27)$ & $15(2 ; 30)$ & $12(5 ; 20)$ \\
\hline Sorensen index & $17(2 ; 57)$ & $16(6 ; 36)$ & $21(3 ; 39)$ & $17(6 ; 27)$ \\
\hline Chao-Sorensen index & $19(3 ; 53)$ & $16(6 ; 34)$ & $22(4 ; 44)$ & $18(7 ; 30)$ \\
\hline
\end{tabular}

${ }^{1} \mathrm{IP}=$ calves housed in individual pens without direct contact with neighboring calves and fed milk or milk replacer 2 to 3 times a day.

${ }^{2} \mathrm{GP}=$ calves housed in group pens with 3 to 25 calves being fed free-choice acidified milk.

${ }^{3}$ Mean richness, diversity, and similarity index estimated between calves within pens. In parenthesis are the minimum and maximum mean values at the farm level.

${ }^{4}$ Mean richness, diversity, and similarity index estimated between calves within farms. In parenthesis are the minimum and maximum mean values at the farm level.

${ }^{5}$ Similarity was calculated by comparing $E$. coli antimicrobial drug susceptibility phenotypes between pairs of calves. Indices are shown as a similarity percentage.

${ }^{6}$ Mean percent of resistance phenotypes shared by a pair of calves.

Organization (Collignon et al., 2009). Resistance to quinolones can limit therapy options in humans with invasive diseases due to Salmonella spp., Campylobacter spp., and multidrug-resistant Shigella spp. (Collignon et al., 2009).

The health effects of housing calves in group pens under field conditions are not clear and the practice remains controversial (Wells et al., 1997; Lorenz et al., 2011). Many study reports agree that, overall, calves housed in group pens tend to have a higher occurrence of respiratory disease compared with calves housed in individual pens (Hanekamp et al., 1994; Gulliksen et al., 2009). A study by Svensson et al. (2003) observed that calves younger than $90 \mathrm{~d}$ old housed in group pens with 6 to 30 calves had a 2.2 odds ratio for incidence of respiratory disease compared with calves housed in single pens $(P=0.019)$. However, in this same study, calves housed in group pens with 3 to 8 calves had a 0.93 odds ratio of respiratory disease compared with calves housed in individual pens $(P=0.019)$. A later study focusing on the effect of group pen size on health reconfirmed that the risk of respiratory disease can be reduced by reducing the number of calves in a group pen (Svensson and Liberg, 2006). The most common

Table 6. Salmonella serotypes by calf-housing system, source, and farm for 44 environmental Salmonella isolates

\begin{tabular}{|c|c|c|c|c|}
\hline \multirow[b]{2}{*}{ Serovar } & \multicolumn{2}{|c|}{ No. of Salmonella from environment } & \multirow{2}{*}{$\begin{array}{l}\text { \% Salmonella } \\
\text { by sample }\end{array}$} & \multirow{2}{*}{$\begin{array}{c}\text { \% Salmonella } \\
\text { by farm }{ }^{2}\end{array}$} \\
\hline & Pen floor ${ }^{3}$ & Nipple $^{4}$ & & \\
\hline $\mathrm{IP}^{5}(\mathrm{n}=25)$ & 25 & - & $41(25 / 61)$ & $83(5 / 6)$ \\
\hline Cerro & 23 & - & $38(23 / 61)$ & $66(4 / 6)$ \\
\hline Liverpool & 2 & - & $3(2 / 61)$ & $16(1 / 6)$ \\
\hline $\operatorname{GP}^{6}(\mathrm{n}=19)$ & 15 & 4 & $31(19 / 61)$ & $33(2 / 6)$ \\
\hline Cerro & 7 & 4 & $18(11 / 61)$ & $33(2 / 6)$ \\
\hline Newport & 8 & 0 & $13(8 / 61)$ & $16(1 / 6)$ \\
\hline
\end{tabular}

${ }^{1}$ Percent of environmental samples culture positive for Salmonella.

${ }^{2}$ Percent of farms with at least one environmental sample culture positive for the specified Salmonella serovar. ${ }^{3}$ Salmonella isolates cultured from environmental samples of calf housing pen floors. A maximum of 1 isolate was cultured per sample.

${ }^{4}$ Salmonella isolates cultured from environmental samples of nipples used for ad libitum feeding of GP calves. ${ }^{5} \mathrm{IP}=$ calves housed in individual pens without direct contact with neighboring calves and fed milk or milk replacer 2 to 3 times a day.

${ }^{6} \mathrm{GP}=$ calves housed in group pens with 3 to 25 calves being fed free-choice acidified milk. 
range of calves per group pen in our study was 15 to 20 calves, which may have resulted in a higher medication rate of GP calves with antimicrobial drugs used for treatment of bovine respiratory disease (BRD). Furthermore, Baytril (Bayer Animal Health) is the only quinolone drug currently approved for use in commercial dairy cattle in the United States. This is an enrofloxacin drug approved for use in nonlactating dairy cattle less than 20 mo of age for the treatment of BRD and for the control of BRD in animals at high risk of developing BRD associated with Mannheimia haemolytica, Pasteurella multocida, Histophilus somni, and Mycoplasma bovis. A higher occurrence of pneumonia in GP calves followed or preceded by the use of enrofloxacin could potentially be the cause for the observed higher prevalence of resistance to quinolone drugs in GP calves when compared with IP calves. This is in accordance with the descriptive data, where 1 of the 2 most common drugs used on the GP farms was enrofloxacin (Baytril). However, more information on individual animal treatment would be necessary to confirm this hypothesis.

Calves from IP presented a significantly higher proportion of E. coli resistant to ampicillin, ceftiofur, streptomycin, and tetracycline compared with the GP group. Reports have showed a tendency for higher incidences of diarrhea in calves housed in individual pens compared with those housed in group pens being fed milk manually or using an ad libitum automatic milk-feeding (Hänninen et al., 2003; Svensson et al., 2003). Svensson et al. (2003) suggested that this could be occurring because calves in group pens better meet their social and emotional needs and drink their milk in a more natural way (Svensson et al., 2003). This may be relevant to the selection of resistance in IP calves, because diarrhea in calves has previously been associated with identification of antimicrobial drug resistance (Orden et al., 2000; Kaneene et al., 2009). A study by de Verdier et al. (2012) evaluated the relationship between occurrence of diarrhea and prevalence of antimicrobial resistance in fecal $E$. coli. In their study, $E$. coli was isolated from fecal samples of pairs of calves where 1 calf was diagnosed with diarrhea and 1 calf was diagnosed as healthy. Their study only sampled calves not treated with antimicrobial drugs within 2 wk before sampling. They observed a higher prevalence of isolates resistant to ampicillin, tetracycline, streptomycin, and sulfonamide $(P \leq 0.05)$ in calves with diarrhea when compared with healthy calves. The selection of resistance found in diarrheic calves could be due to linkage between virulence genes and resistance genes in $E$. coli causing diarrhea in calves (Martínez and Baquero, 2002). In the de Verdier et al. (2012) study, phenotypic resistance to one or more antimicrobial drugs was as- sociated with the presence of $3 \mathrm{E}$. coli virulence genes. The administration of broad-spectrum $\beta$-lactams, such as ampicillin (e.g., Polyflex, Boehringer Ingelheim Vetmedica, St. Joseph, MO) and ceftiofur (e.g., Excenel RTU, Pfizer Animal Health, Exton, Pennsylvania), to treat diarrhea in calves could also be a factor in the selection of resistance to antimicrobial drugs in IP calves (Constable, 2004). The fact that the 2 most commonly used antimicrobials on IP farms were $\beta$-lactams (ceftiofur and penicillin $\mathrm{G}$ ) corroborates the hypothesis that more animals may have been treated for diarrhea on IP farms, and that selection for resistance to $\beta$-lactams could have also occurred because of the therapeutic use of these drugs.

To our knowledge, the higher proportion of resistance to gentamicin observed in IP isolates has not been previously related to diarrhea in calves. However, a study by Ahmed et al. (2009) identified class 1 integrons in up to $10.4 \%$ of $E$. coli isolates from calves with diarrhea. Integrons are mobile DNA elements capable of encoding multiple resistance genes at once (Gillings et al., 2008). Furthermore, diarrhea could have resulted in the selection of E. coli-carrying class 1 integrons that resulted in co-selection of resistance to gentamicin. Moreover, characterization of class 1 integron-mediated antibiotic resistance among $E$. coli from calves has revealed the capability to integrate antimicrobial resistance genes to antimicrobial classes, such as $\beta$-lactams and aminoglycosides (Du et al., 2005). Resistance to these antimicrobial classes was observed in higher prevalences in IP isolates compared with GP isolates, and could have resulted in co-selection of gentamicin.

Dietary differences between IP and GP calves could also play a role in the selection advantage of resistant bacteria on IP farms. A study by Khachatryan et al. (2006) observed that feeding preweaned calves milk with an added nonmedicated dietary supplement composed of nonfat dry milk and vitamins contributed to a significantly higher prevalence of fecal $E$. coli resistant to streptomycin, sulfadiazine, and tetracycline when compared with calves fed milk without the addition of the supplement. The researchers' hypothesis for this finding was that a genetic linkage of the streptomycin, sulfadiazine, and tetracycline determinants to other genes may exist and confer a selective advantage in the presence of the dietary supplement. The difference in the proportion of antimicrobial drug resistance between IP and GP calves may be related both to dissimilarities in the nutrients in acidified and nonacidified milk or milk replacer as well as the volume and frequency of feed consumed. Acidification of milk has been shown to have little to no effect on milk nutrients commonly considered of major importance, such as fat and CP (Woodford et al., 1987; Hill et al., 2013). However, 
it has been claimed that the lower $\mathrm{pH}$ of milk and frequency of meals of GP calves could diminish diurnal $\mathrm{pH}$ fluctuations in the abomasum, resulting in a lower $\mathrm{pH}$ in the digestive tract and a reduction in the amount of pathogens (Hepola, 2003; Guler et al., 2006). Preweaned calves provided milk ad libitum have been shown to have more frequent meals (up to 7 meals a day) and more evenly distributed diurnal patterns of feeding activity compared with the restrictive feeding of milk twice a day (Miller-Cushon et al., 2013).

Independent of the calf-housing system, a shift in the proportion of resistant isolates by age group was observed in our study (Table 3 ). The variance in antimicrobial drug resistance observed between calf-housing systems at different age groups could be a consequence of changes in the microbiota due to different feeding protocols in IP and GP. A study by Berge et al. (2005) observed that calves $2 \mathrm{wk}$ of age were more likely to have multidrug-resistant $E$. coli compared with calves 4 and 6 wk old ( $\mathrm{OR}=29.8$ and 16.4, respectively). Lack of a developed intestinal microflora in young calves could be a factor resulting in higher colonization of younger calves by resistant bacteria. A degree of protection against colonization by bacteria with a higher fitness cost, such as antimicrobial-resistant bacteria and pathogenic enteric bacteria, may follow as the calves' indigenous microflora matures and the enteric microbiota diversity increases, resulting in a decreased prevalence of resistant bacteria (Cummings et al., 2009; Oikonomou et al., 2013). Studies evaluating the effects of feeding preweaned calves acidified and nonacidified milk on the composition of the gastro-intestinal microbiota are needed to test this assumption.

\section{Distribution of E. coli Antimicrobial Susceptibility Phenotypes}

Calves in GP presented a higher prevalence of multidrug resistant phenotypes than IP calves did, as seen in Table 4. To observe if the accumulation of $E$. coli ADSP between calf-housing system types clustered differently at the pen and farm levels, a rarefaction curve was used to visualize the richness of ADSP. Similar results for most rarefaction curves within GP pens and farms were observed, with signs of reaching an asymptote earlier than in IP pens and farms (Figure 1). Rarefaction curves reach an asymptote faster when accumulation occurs with fewer numbers of isolates. Therefore, when no new ADSP is added, an asymptote should be reached (Gotelli and Colwell, 2001). The rarefaction curve indicates that GP isolates are distributed in fewer ADSP, suggesting less richness of isolates. Because not all rarefaction curves reached an asymptote, ADSP richness was estimated using Chao's asymptotic mathematical function (Magurran and McGill, 2011). A slightly lower and narrower range for the mean Chao richness index and Shannon diversity index calculated at the pen and farm level were observed for GP isolates compared with IP isolates.

Moreover, mean similarity indices of E. coli ADSP between pairs of calves were higher between calves in GP than calves in IP (Table 5). A potential cause for these findings is that commingling of calves in group pens increases the exchange of bacteria and resistance genes between calves, resulting in a more homogenous distribution of $E$. coli ADSP between calves in GP. Although commingling may play a role in the distribution of E. coli ADSP, we did not observe a significant difference in richness, diversity, and similarity indices between GP and IP isolates, indicating that it probably is not the main factor in the spread of antimicrobial resistant commensal E. coli.

\section{Distribution of Environmental Salmonella Serovars}

Salmonella enterica serovar Cerro was the most common serovar observed in farm environmental samples. This is in accordance with a recent study that reported Cerro as the most common serotype among 1,174 dairy cattle isolates from dairy farms in the northeastern United States between 2004 and 2011 (Cummings et al., 2013). More IP farms (83\%) had at least 1 Salmonella colony isolated from environmental samples compared with GP farms (33\%; Table 6). An interesting finding among GP farms was the isolation of S. enterica serovar Cerro from the feeding nipples shared by calves. Although the role of $S$. enterica serovar Cerro in causing clinical illness among dairy cattle is still unclear, the isolation of Cerro from the feeding nipples represents a potential source for the dissemination of pathogenic bacteria in a group pen, reinforcing the importance of frequent sanitation and replacement of feeding nipples on GP farms (Cummings et al., 2010).

\section{CONCLUSIONS}

The calf-housing system has an effect on resistance to individual antimicrobial drugs in E. coli, but no clearcut advantage to either system with regard to overall resistance frequency was observed. Calves in GP had a significantly higher proportion of $E$. coli resistant to ciprofloxacin and nalidixic acid, whereas calves in IP had a significantly higher proportion of $E$. coli resistant to ampicillin, ceftiofur, gentamicin, streptomycin, and tetracycline. No outstanding difference in the richness and diversity of resistant phenotypes was noted between the 2 calf-housing systems. Salmonella Cerro was the most commonly isolated serotype in environmental 
samples from all farms. Salmonella was isolated from feeder nipples on GP farms, raising the importance of frequent sanitation and replacement of shared feeding nipples in group pens.

\section{ACKNOWLEDGMENTS}

We thank Pepi Leids from the New York State Cattle Health Assurance Program (Albany, NY) for assisting with the enrollment of farms in this project. Research reported in this publication was supported by the Agriculture and Food Research Initiative Competitive Grant no. 2010-51110-21131 from the USDA National Institute of Food and Agriculture (Washington, DC). The content is solely the responsibility of the authors and does not necessarily represent the official views of the USDA. Research reported in this publication was supported by the Office of the Director, National Institutions of Health (Bethesda, MD), under Award Number T32ODO011000. The content is solely the responsibility of the authors and does not necessarily represent the official views of the National Center for Research Resources or the National Institutes of Health.

\section{REFERENCES}

Ahmed, A. M., E. E. Younis, S. A. Osman, Y. Ishida, S. A. El-Khodery, and T. Shimamoto. 2009. Genetic analysis of antimicrobial resistance in Escherichia coli isolated from diarrheic neonatal calves. Vet. Microbiol. 136:397-402.

Berge, A. C., E. R. Atwill, and W. M. Sischo. 2005. Animal and farm influences on the dynamics of antibiotic resistance in faecal Escherichia coli in young dairy calves. Prev. Vet. Med. 69:25-38.

Bernal-Rigoli, J. C., J. D. Allen, J. A. Marchello, S. P. Cuneo, S. R. Garcia, G. Xie, L. W. Hall, C. D. Burrows, and G. C. Duff. 2012 Effects of housing and feeding systems on performance of neonatal Holstein bull calves. J. Anim. Sci. 90:2818-2825.

CLSI. 2008a. Performance Standards for Antimicrobial Disk and Dilution Susceptibility Tests for Bacteria Collected from Animals Approved Standards. 3rd ed. Clinical and Laboratory Standards Institute, Wayne, PA.

CLSI. 2008b. Performance Standards for Antimicrobial Disk and Dilution Susceptibility Tests for Bacteria Isolated from Animals: Approved Standard. Clinical and Laboratory Standards Institute. Clinical and Laboratory Standards Institute, Wayne, PA.

Collignon, P., J. H. Powers, T. M. Chiller, A. Aidara-Kane, and F. M. Aarestrup. 2009. World health organization ranking of antimicrobials according to their importance in human medicine: A critical step for developing risk management strategies for the use of antimicrobials in food production animals. Clin. Infect. Dis. 49:132-141.

Colwell, R. K. 2013. EstimateS: Statistical estimation of species richness and shared species from samples, version 9.1.0. R. K. Cowell, Storrs, CT.

Constable, P. D. 2004. Antimicrobial use in the treatment of calf diarrhea. J. Vet. Intern. Med. 18:8-17.

Cummings, K. J., V. A. Aprea, and C. Altier. 2014. Antimicrobial resistance trends among Escherichia coli isolates obtained from dairy cattle in the northeastern United States, 2004-2011. Foodborne Pathog. Dis. 11:61-67.

Cummings, K. J., G. A. Perkins, S. M. Khatibzadeh, L. D. Warnick, and C. Altier. 2013. Antimicrobial resistance trends among Salmo- nella isolates obtained from dairy cattle in the northeastern United States, 2004-2011. Foodborne Pathog. Dis. 10:353-361.

Cummings, K. J., L. D. Warnick, K. A. Alexander, C. J. Cripps, Y. T. Gröhn, P. L. McDonough, D. V. Nydam, and K. E. Reed. 2009 The incidence of salmonellosis among dairy herds in the northeastern United States. J. Dairy Sci. 92:3766-3774.

Cummings, K. J., L. D. Warnick, M. Elton, L. D. Rodriguez-Rivera, J. D. Siler, E. M. Wright, Y. T. Grohn, and M. Wiedmann. 2010. Salmonella enterica serotype Cerro among dairy cattle in New York: An emerging pathogen? Foodborne Pathog. Dis. 7:659-665.

de Verdier, K., A. Nyman, C. Greko, and B. Bengtsson. 2012. Antimicrobial resistance and virulence factors in Escherichia coli from Swedish dairy calves. Acta Vet. Scand. 54:2.

Du, X., Z. Shen, B. Wu, S. Xia, and J. Shen. 2005. Characterization of class 1 integrons-mediated antibiotic resistance among calf pathogenic Escherichia coli. FEMS Microbiol. Lett. 245:295-298.

Gillings, M., Y. Boucher, M. Labbate, A. Holmes, S. Krishnan, M. Holley, and H. W. Stokes. 2008. The evolution of class 1 integrons and the rise of antibiotic resistance. J. Bacteriol. 190:5095-5100.

Gotelli, N. J., and A. Chao. 2013. Measuring and estimating species richness, species diversity, and biotic similarity from sampling data. Pages 195-211 in Encyclopedia of Biodiversity. 2nd ed., vol. 5. Academic Press, Waltham, MA

Gotelli, N. J., and R. K. Colwell. 2001. Quantifying biodiversity: Procedures and pitfalls in the measurement and comparison of species richness. Ecol. Lett. 4:379-391.

Gow, S. P., C. L. Waldner, J. Harel, and P. Boerlin. 2008. Associations between antimicrobial resistance genes in fecal generic Escherichia coli isolates from cow-calf herds in western Canada. Appl. Environ. Microbiol. 74:3658-3666.

Guler, O., M. Yanar, B. Bayram, and J. Metin. 2006. Performance and health of dairy calves fed limited amounts of acidified milk replacer. S. Afr. J. Anim. Sci. 36:149-154.

Gulliksen, S. M., E. Jor, K. I. Lie, T. Loken, J. Akerstedt, and O. Osteras. 2009. Respiratory infections in Norwegian dairy calves. J. Dairy Sci. 92:5139-5146.

Hanekamp, W. J. A., A. C. Smits, and H. K. Wierenga. 1994. Open versus closed barn and individual versus group-housing for bull calves destined for beef production. Livest. Prod. Sci. 37:261-270.

Hepola, H. 2003. Milk feeding systems for dairy calves in groups: Effects on feed intake, growth and health. Appl. Anim. Behav. Sci. 80:233-243.

Hill, T. M., H. G. Bateman 2nd, J. M. Aldrich, J. D. Quigley, and R. L. Schlotterbeck. 2013. Evaluation of ad libitum acidified milk replacer programs for dairy calves. J. Dairy Sci. 96:3153-3162.

Hoelzer, K., K. J. Cummings, L. D. Warnick, Y. H. Schukken, J. D. Siler, Y. T. Grohn, M. A. Davis, T. E. Besser, and M. Wiedmann. 2011. Agar disk diffusion and automated microbroth dilution produce similar antimicrobial susceptibility testing results for Salmonella serotypes Newport, Typhimurium, and 4,5,12:I-, but differ in economic cost. Foodborne Pathog. Dis. 8:1281-1288.

Hänninen, L., H. Hepola, J. Rushen, A. M. de Passillé, P. Pursiainen, V. Tuure, L. Syrjälä-qvist, M. Pyykkönen, and H. Saloniemi. 2003. Resting behaviour, growth and diarrhoea incidence rate of young dairy calves housed individually or in groups in warm or cold buildings. Acta Agric. Scand. A Anim. Sci. 53:21-28.

Kaneene, J. B., L. D. Warnick, C. A. Bolin, R. J. Erskine, K. May, and R. Miller. 2009. Changes in multidrug resistance of enteric bacteria following an intervention to reduce antimicrobial resistance in dairy calves. J. Clin. Microbiol. 47:4109-4112.

Khachatryan, A. R., T. E. Besser, D. D. Hancock, and D. R. Call 2006. Use of a nonmedicated dietary supplement correlates with increased prevalence of streptomycin-sulfa-tetracycline-resistant Escherichia coli on a dairy farm. Appl. Environ. Microbiol. 72:4583-4588.

Kung, L., Jr., S. Demarco, L. N. Siebenson, E. Joyner, G. F. Haenlein, and R. M. Morris. 1997. An evaluation of two management systems for rearing calves fed milk replacer. J. Dairy Sci. 80:2529-2533.

Linton, A. H., K. Howe, S. Pethiyagoda, and A. D. Osborne. 1974. Epidemiology of Salmonella infection in calves (1): Its relation to their husbandry and management. Vet. Rec. 94:581-585. 
Lorenz, I., B. Earley, J. Gilmore, I. Hogan, E. Kennedy, and S. J. More. 2011. Calf health from birth to weaning. III. Housing and management of calf pneumonia. Ir. Vet. J. 64:14.

MacGregor-Fors, I., and M. E. Payton. 2013. Contrasting diversity values: Statistical inferences based on overlapping confidence intervals. PLoS ONE 8:e56794.

Magurran, A. E., and B. J. McGill. 2011. Biological Diversity: Frontiers in Measurement and Assessment. Oxford University Press, New York, NY.

Martínez, J. L., and F. Baquero. 2002. Interactions among strategies associated with bacterial infection: Pathogenicity, epidemicity, and antibiotic resistance. Clin. Microbiol. Rev. 15:647-679.

Miller-Cushon, E. K., R. Bergeron, K. E. Leslie, and T. J. DeVries. 2013. Effect of milk feeding level on development of feeding behavior in dairy calves. J. Dairy Sci. 96:551-564.

O'Driscoll, K., M. A. von Keyserlingk, and D. M. Weary. 2006. Effects of mixing on drinking and competitive behavior of dairy calves. J. Dairy Sci. 89:229-233.

Oikonomou, G., A. G. Teixeira, C. Foditsch, M. L. Bicalho, V. S. Machado, and R. C. Bicalho. 2013. Fecal microbial diversity in pre-weaned dairy calves as described by pyrosequencing of metagenomic 16S rDNA. Associations of Faecalibacterium species with health and growth. PLoS ONE 8:e63157.

Orden, J. A., J. A. Ruiz-Santa-Quiteria, S. Garcia, D. Cid, and R. De La Fuente. 2000. In vitro susceptibility of Escherichia coli strains isolated from diarrhoeic dairy calves to 15 antimicrobial agents. J. Vet. Med. B Infect. Dis. Vet. Public Health 47:329-335.
Pereira, R. V., T. M. Santos, M. L. Bicalho, L. S. Caixeta, V. S. Machado, and R. C. Bicalho. 2011. Antimicrobial resistance and prevalence of virulence factor genes in fecal Escherichia coli of Holstein calves fed milk with and without antimicrobials. J. Dairy Sci. 94:4556-4565.

Svensson, C., and P. Liberg. 2006. The effect of group size on health and growth rate of Swedish dairy calves housed in pens with automatic milk-feeders. Prev. Vet. Med. 73:43-53.

Svensson, C., K. Lundborg, U. Emanuelson, and S. O. Olsson. 2003 Morbidity in Swedish dairy calves from birth to 90 days of age and individual calf-level risk factors for infectious diseases. Prev. Vet. Med. 58:179-197.

USDA. 2011. United States Cattle and Calf Inventory: January 2011. United States Department of Agriculture, Washington, DC.

Waltner-Toews, D., S. W. Martin, and A. H. Meek. 1986. Dairy calf management, morbidity and mortality in Ontario Holstein herds. III. Association of management with morbidity. Prev. Vet. Med. 4:137-158.

Warnick, V. D., C. W. Arave, and C. H. Mickelsen. 1977. Effects of group, individual, and isolated rearing of calves on weight gain and behavior. J. Dairy Sci. 60:947-953.

Wells, S. J., D. A. Dargatz, and S. L. Ott. 1997. Factors associated with mortality to 21 days of life in dairy heifers in the United States. Prev. Vet. Med. 29:9.

Woodford, S. T., H. D. Whetstone, M. R. Murphy, and C. L. Davis. 1987. Abomasal pH, nutrient digestibility, and growth of Holstein bull calves fed acidified milk replacer. J. Dairy Sci. 70:888-891. 